\title{
A Educação Física no ensino médio como objeto de estudo da produção acadêmico-científica nos periódicos nacionais
}

CDD. 20.ed. 373

796.017

\author{
Diogo Inacio DIAS* \\ Walter Roberto CORREIA* \\ *Escola de Educa- \\ ção Física e Esporte, \\ Universidade de São \\ Paulo.
}

\begin{abstract}
Resumo
0 presente trabalho teve por objetivo descrever e caracterizar a inserção da temática Educação Física no Ensino Médio no âmbito dos periódicos nacionais de Educação Física e Esporte (período 2005-2010). Foram explorados 3313 artigos publicados em periódicos classificados nos extratos A e B do sistema Qualis/CAPES. Destes, 31 artigos (1,06\%) trazem a temática da Educação Física no Ensino Médio. Baseando-se na proposição de Antunes et al. ${ }^{14}$, foi possivel classificar estes 31 artigos nas seis categorias seguintes: Processo Ensino-Aprendizagem e Indefinido: oito artigos (25,80\% cada); Finalidade: sete (22,6\%); Caracterização: seis (19,35\%); Epistemologia: dois (6,5\%); e Formação de Professores: nenhum artigo (0\%). Os dados revelam uma restrição na produção de conhecimento no campo da Educação Física e Educação Física no Ensino Médio, sugerindo a necessidade de desenvolver um entrecruzamento estratégico das dimensões epistemológicas da área com as pesquisas de caráter aplicado, perpassando pelas questões inerentes ao processo de formação docente.
\end{abstract}

Palavras-chave: Educação física escolar; Ensino médio; Produção acadêmica.

\section{Introdução}

Podemos dizer que a educação, num sentido mais amplo, sempre existiu ${ }^{1}$, e que a mesma pode vir a cumprir um papel de grande importância e protagonismo na vida do indivíduo, sobretudo no que diz respeito aos aspectos da sociabilização.

Assumindo que ao longo da trajetória da humanidade, houve, desde o princípio, a necessidade de se elaborarem instrumentos (objetos), formas de linguagem, em outras palavras, meios de sobrevivência, e que concomitantemente houve também a transmissão deste legado às novas gerações (via mecanismos também criados por estes seres), garantindo assim a sobrevivência da espécie (e aqui desconsideramos as adaptações impostas pelo meio ambiente, que não se fixam biologicamente na carga genética $)^{1}$, podemos então, dizer que a EDUCAÇÃO, como nos aponta o autor, sempre existiu.

Ainda dentro deste panorama, como nos revela PÉrez GOMEZ ${ }^{2}$, nos grupos humanos mais reduzidos e nas sociedades mais primitivas, o processo de aprendizagem se dava através de uma sociabilização direta, processo este no qual a geração mais nova, através de participação cotidiana nas atividades "adultas", aprendia o necessário para a vida em comunidade.

Entretanto, em dado momento da trajetória da história da humanidade, com a aceleração do desenvolvimento das comunidades humanas, somada a um processo mais complexo de convívio, funcionamento, atribuiçôes e açôes dentro de cada comunidade (diversificação das funçôes, aumento do número de tarefas e deveres, aumento do número de indivíduos que compõe a comunidade, etc.), surgiu a necessidade de criar mecanismos de sociabilização mais eficazes e eficientes para suprir as demandas de grupos sociais como a família ou os grupos de trabalho, por exemplo.

Para tanto, surgem, então, outras formas de especialização (tutor, preceptor, academia, escola laica, escola religiosa, etc), que além de modificar profundamente o processo de educação e de sociabilização do indivíduo, trouxeram um ganho fundamental no que diz respeito à constituição, nas sociedades industriais contemporâneas, da educação e do processo de escolarização obrigatória a todas as camadas populacionais ${ }^{2}$. 
Chegamos assim à função social de escola, que enquanto agente social tem justamente o papel de ser a instituição que desenvolve o processo de sociabilização das novas gerações, garantindo assim a reprodução social e cultural como grande requisito necessário para que o indivíduo consiga manter sua sobrevivência e também a sobrevivência da sociedade em que vive ${ }^{2}$.

Do ponto de vista legal, a Lei de Diretrizes e Bases da Educação Nacional - LDBEN ${ }^{3}$, nos aponta três aspectos fundamentais que legitimam a educação escolarizada em instituição própria e que cumpre um papel fundamental no desenvolvimento do indivíduo:

\section{TÍTULO I}

Da Educação

Art. $1^{\circ}$. A educação abrange os processos formativos que se desenvolvem na vida familiar, na convivência humana, no trabalho, nas instituiçōes de ensino e pesquisa, nos movimentos sociais e organizaçōes da sociedade civil e nas manifestaçôes culturais.

$\$ 1^{\circ}$. Esta Lei disciplina a educação escolar, que se desenvolve, predominantemente, por meio do ensino, em instituiçōes próprias.

$\$ 2^{\circ}$. A educação escolar deverá vincular-se ao mundo do trabalho e à prática social (p.1).

Dentro ainda do ponto de vista da legislação, veremos que a $\mathrm{LDBEN}^{3}$, no seu Título II, nos aponta que a educação é um dever da família e do Estado, deve ser inspirada em princípios como o da liberdade, nos ideais da solidariedade humana, e tem como objetivo o pleno desenvolvimento do educando, seu preparo para exercer a cidadania e qualificar-se para o trabalho. Ou seja, até este ponto temos provas suficientes do valor e da necessidade da educação formal, e mais especificamente da escola para o desenvolvimento do indivíduo.

Dentro deste processo de educação, que se dá no ambiente escolar, encontraremos uma espinha dorsal que sustentará o processo de aprendizagem do indivíduo na escola, o currículo. ColL ${ }^{4}$ acredita ser o currículo um processo de elaboração e realização das intenções educativas. E estas intenções educativas são constituídas por níveis interligados e racionalizados de concretização do currículo, são frutos do processo que torna o currículo concreto. Neste, são socializados e construídos saberes socialmente relevantes, de origens conceituais, procedimentais, atitudinais e referentes a valores. Este currículo trará uma série de conteúdos que podem ser definidos como uma seleção de saberes culturais, conceitos, habilidades, explicações, raciocínios, etc. ${ }^{5}$. Entretanto vale a ressalva de LiBÂNEO ${ }^{6}$ e COLL et al. ${ }^{5}$ de que nem todos os saberes e formas culturais presentes no universo da cultura (e da sociedade) são necessariamente passíveis de estarem presentes no currículo escolar como conteúdos escolares. ColL ${ }^{4}$ ainda diz que tal processo exige um conjunto de esforços de diferentes instâncias e sujeitos, e todos devem estar dispostos, "abraçar" a ideia de realizar uma autêntica criação de cultura a fim de favorecer a inserção dos diferentes grupos sociais na dinâmica social, de forma mais ampliada.

Partindo agora para outra análise que pode se mostrar útil e relevante para a discussão em questão, e considerando este panorama exposto acima, chegamos aos componentes curriculares que compõem a grade curricular escolar, dentre eles a Educação Física. CORREIA $^{7}$ defende que a Educação Física é um componente curricular que tem como proposição oferecer conhecimentos de natureza teórica e prática a partir de um conceito mais amplo do que o autor chama "Educação Corporal", podendo assim contribuir, de maneira significativa, para uma ampliação relativa da democratização dos saberes e intenções educacionais/ escolares. Ou seja, através dos conhecimentos de áreas como a Pedagogia, Psicologia, Antropologia, Sociologia, Química, Biologia, Fisiologia, Biomecânica, etc., a Educação Física poderá tratar da educação do indivíduo por meio dos conhecimentos e saberes relativos à Cultura Corporal de Movimento.

Considerando o ser humano como uma unidade de corpo e mente, ser biológico e ser social, membro de uma espécie humana e ser participante de um processo histórico ${ }^{8}$, a Educação Física é o componente curricular que lida com as questóes relativas a cultura corporal de movimento ${ }^{7}$. O profissional de Educação Física (no caso professor de Educação Física Escolar) tratará do ser humano nas respectivas manifestações culturais relacionadas ao corpo e ao movimento humano, movimentos estes historicamente definidos como jogo, esporte, dança, luta e ginástica ${ }^{9}$ e por se tratar do ambiente escolar, terá como pano de fundo as intenções pedagógicas da escola (ou seu Projeto Político Pedagógico).

Os Parâmetros Curriculares Nacionais ${ }^{3}$ também colocam a Educação Física como um componente curricular fundamental para a formação do indivíduo, indicando que seus conteúdos (nas dimensões conceitual, procedimental e atitudinal) oferecem subsídios pertinentes para a concretização das intençốes educacionais da escola.

Recorrendo outra vez à legislação, segundo a $\$ 3^{\circ}$ do Art. $26^{\circ}$ do capítulo II da LDBEN $^{3}$ a Educação Física (integrada à proposta pedagógica da instituição de ensino, ajustada às demandas e características das 
faixas etárias e ao contexto populacional) é componente da educação básica (Educação Infantil, Ensino Fundamental e Ensino Médio), sendo facultativa apenas nos cursos noturnos. Ou seja, legalmente a Educação Física tem respaldo para fazer parte da grade curricular escolar, desempenhando papel de significativa relevância na formação do indivíduo.

Para efeito deste trabalho, consideraremos o universo do Ensino Médio (último ciclo da escolarização básica). De acordo com a $\mathrm{LDBEN}^{3}$, o ensino Médio tem como missão o aprofundamento de conhecimentos, o desenvolvimento do pensamento crítico, dos fundamentos tecnológicos, de uma atitude ética, a valorização das artes, da literatura e o aperfeiçoamento da condição humana. Ou seja, a escola e seu papel social, deveriam, dentro do possível, caminhar coerentemente na direção destes indicativos legais, favorecendo assim, uma educação voltada para a cidadania, preparação para o trabalho, oferecendo condiçôes para que o indivíduo prossiga seus estudos posteriormente à educação básica (na Universidade, em cursos profissionalizantes, de maneira autodidata, etc.), proporcionando assim formação ampla, integral e continuada deste indivíduo. Assim sendo, os componentes curriculares assumiriam um compromisso de se mobilizarem para atender a estas perspectivas educativas, prezando pela inclusão e a democracia, como nos aponta CORREIA ${ }^{7}$.

Dentro desta perspectiva do Ensino Médio, o componente curricular Educação Física, como nos mostra CORREIA ${ }^{10}$, pode desempenhar um papel de bastante relevância social no âmbito do Ensino Médio a partir dos conhecimentos (sistematizados e aprofundados) sobre os aspectos relativos à cultura corporal de movimento.

Para a Proposta Curricular de Estado de São Pau$\mathrm{lo}^{11}$, a Educação Física no Ensino Médio, compreendendo um indivíduo mergulhado em um ambiente repleto de realidades culturais diferentes, nas quais não há a dissociação entre corpo, movimento e intencionalidade, proporciona ao aluno não só vivenciar, experimentar, apreciar, valorizar estes benefícios vindos da cultura relacionada ao movimento humano, mas também e, sobretudo, perceber e compreender os sentidos e significados destas manifestações corporais na sociedade em que vive.

DARIDO $^{12}$ defende a Educação Física no Ensino Fundamental e Médio e alinhado aos apontamentos de BETTI $^{13}$ acredita que a Educação Física como integrante do currículo escolar possa desempenhar um papel pedagógico fundamental que vai para além da dimensão prática da cultura corporal, mas que chega até horizontes como o contexto no qual se desenvolve a prática, às características e influências deste contexto, por exemplo. Deixaria assim de ser a Educação Física um discurso sobre as práticas corporais e passaria a ser uma ação pedagógica que dialoga a todo instante com a cultura corporal ${ }^{13}$.

Uma vez determinado o papel social da educação e da escola, e dentro desta escola o papel social da Educação Física, sobretudo no que tange o Ensino Médio, chegamos o ponto chave e ao foco deste trabalho.

Entendo a Educação Física como uma área onde há a presença de elementos como educação e intervenção sociocultural, e considerando que para esta manter-se como tal é necessário que haja um embasamento teórico acadêmico que a sustente, tomaremos como referência, para esta análise, o trabalho de ANTUnes al. ${ }^{14}$ que nos traz dados acerca da produção acadêmica em Educação Física escolar. No referido estudo os autores buscavam apresentar um quadro dos artigos publicados em periódicos nacionais e internacionais (no período 1999-2003) e que se referissem à Educação Física, mais especificamente à Educação Física escolar. E baseado nisto, os autores objetivavam elaborar um conjunto de critérios que permitissem uma classificação do tipo de pesquisas relativas ao contexto escolar que eram produzidas neste período temporal, além de explicitar uma proposta acerca da natureza do conhecimento da Pedagogia da Educação Física escolar (PEFE) - assumindo aqui a PEFE como subárea de pesquisa da Educação Física, que procura investigar os aspectos relacionados ao ensino da Educação Física como disciplina curricular, abordando aspectos teóricos (epistemologia e finalidade) e também os aspectos da aplicação (processo Ensino-Aprendizagem, caracterização do ambiente/ contexto escolar, formação de professores).

Como resultado, os autores apontam que o contexto escolar é um objeto de estudo não privilegiado no que diz respeito ao universo da Educação Física. Também ressaltam que quando a Educação Física escolar é abordada, o tema Processo de EnsinoAprendizagem (que deveria ser alvo das investigações na visão dos autores em questão) não é tema prioritário das investigações. Os autores ainda apontam que este quadro encontrado é preocupante, pois há um nítido déficit de conhecimentos academicamente elaborados acerca da prática pedagógica escolar.

Pensado agora na ótica da prática docente, mais especificamente do docente da Educação Básica, e considerando a avaliação que ANTUNES al. ${ }^{14}$ fazem acerca da produção acadêmica em Educação Física escolar (no período 1999-2003), um mapeamento 
desta produção (mesmo que em uma quantidade relativamente restrita, como nos aponta o estudo em questão), pode vir a servir como ferramenta para este docente buscar referencial teórico para pautar, refletir, avaliar, planejar, replanejar sua prática, por exemplo.

Dando continuidade, observamos que do ponto de vista da formação de professores um fator relevante no processo é justamente trazer e ter referencial teórico vasto, diversificado e significativo que pode inclusive auxiliar o próprio processo. Tais benefícios poderiam estar relacionados à informações acerca de bibliografia para esclarecer dúvidas (não só conceituais, mas também procedimentais, e outras naturezas) dos alunos de cursos de formação de professores, ou então apresentarem-se como uma forma de complemento da formação curricular básica, ou ainda figurarem como ferramenta integrante de um processo de formação continuada de maneira mais ampla (como apresenta e discute NóvOA ${ }^{15}$ ).

Ainda em outra análise, e em concordância com o apontamento de BrachT ${ }^{16}$ e LOVISOLO ${ }^{17}$ de que a Educação Física no campo acadêmico tem uma especificidade que a caracteriza como uma prática pedagógica, é possível de se dizer que a Educação Física assume um papel pedagógico particular, sobretudo no que diz respeito ao currículo escolar, e às práticas pedagógicas da e na escola.

Considerando então que a escola cumpre um papel fundamental e insubstituível no processo de formação do indivíduo ${ }^{1-2}$, e que justamente pelo fato de a Educação Física se apresentar como componente do currículo escolar, esta (tal qual os outros componentes curriculares), mereceria, no nosso modo de ver, uma posição de maior destaque nas investigaçóes e produçōes de cunho acadêmico-científico. Sendo assim, pode tornar-se pertinente não só elucidar quantitativamente a produção acadêmica nacional em Educação Física Escolar, mais especificamente no Ensino Médio, mas também caracterizá-la quanto a sua temática.

\section{Método}

Para efeito deste trabalho, cujo foco de análise foi a produção de conhecimento nos periódicos nacionais (entre os anos de 2005 a 2010) no âmbito da Educação Física escolar no Ensino Médio em periódicos que se remetam à temática da Educação Física, a seleção dos mesmos, dos quais se extraíram os dados para a realização deste estudo foi elaborada a partir dos seguintes critérios:
Poderíamos então, desta forma, gerar um fator auxiliador que transitasse por campos como a formação de professores, perpassando pela prática docente, até a produção de conhecimento via pesquisa científica, podendo inclusive lançar hipóteses para explicar possíveis restrições ou limitações na produção de conhecimento na referida área de conhecimento em detrimento de outras.

Isto posto, faz-se necessário um último esclarecimento. Optou-se pela escolha do período temporal 2005-2010 pelo fato de este ter sido marcado por acontecimentos significativos no âmbito da Educação brasileira (em campos como políticas públicas, financiamento, planejamento, etc.). Entre alguns destes acontecimentos podemos destacar, por exemplo, a revisão do Plano Nacional de Educação, a implantação de propostas pedagógicas em diferentes Estados e municípios (concepção e implantação), a criação de instrumentos de avaliação em diferentes níveis da educação básica (como o SARESP, ENEM, ENADE, etc), e a expansão da Pós-Graduação brasileira com um impactante crescimento da produção de conhecimento científico, assim como investimentos no que diz respeito a formação superior com programas de financiamento estudantil como o ProUni.

No que diz respeito aos periódicos elencados, fizemos a opção por periódicos nacionais pelo fato de que, notoriamente, estes, ao longo da década passada, passaram a receber cada vez mais enfoque e atenção por parte de autores e produtores de conhecimento academicamente orientado (artigos, dissertações, teses, projetos de pesquisas, relatos). Isso pode ser percebido analisando-se o montante de artigos produzidos e submetidos à periódicos nacionais na década de 90 e comparando com os números a partir do ano 2000. Não só o montante de submissões sofreu alteraçóes, mas também é possível observar algo semelhante no número de periódicos relacionados à área 21 no Qualis CAPES, por exemplo.

1) Todos os periódicos de onde se obtiveram os artigos para efeito de análise estão circunscritos ao âmbito nacional, presentes na Área 21 do Qualis CAPES (Coordenação de Aperfeiçoamento de Pessoal de Nível Superior) - ano 2007-2009, além de qualificados nos extratos A e B deste mesmo sistema;

2) Os periódicos utilizados para a coleta dos dados deveriam ser veículos de publicação de trabalhos, e 
não divulgação. Configurando-se assim um processo de produção de conhecimento, uma vez que são consideradas apenas as publicaçôes inéditas;

3) Considerou-se a presença dos termos Educação Física, Educação Física escolar, Esporte, Corpo, Movimento, Motricidade (e outros derivados do termo) e Atividade Física no título do periódico. Entendendo que os mesmos perpassam pela especificidade da área em questão;

4) Também foi considerada para a referida seleção a disponibilidade do sumário e resumos dos artigos dos periódicos em mídia eletrônica para consulta, visando uma posterior identificação e análise de estudos relacionados especificamente ao cerne deste trabalho.

Uma vez observados os critérios elencados acima, chegou-se ao universo destes 16 periódicos (todos ranqueados nos extratos $\mathrm{B} 1 \mathrm{a} \mathrm{B} 5$ - não há periódicos A1 e A2 segundo o Qualis/CAPES 2007-2009): Revista Ação e Movimento, Arquivos em Movimento, Coleção Pesquisa em Educação Física, Caderno de Educação Física, Revista Corpoconsciência, Revista Esporte e Sociedade, Revista Motriz, Revista Movimento, Revista Brasileira de Atividade Física e Saúde, Revista Brasileira de Ciência e Movimento, Revista Brasileira de Ciências do Esporte, Revista Brasileira de Educação Física e Esporte, Revista da Educação Física, Revista Mackenzie de Educação Física e Esporte, Revista Mineira de Educação Física, Revista Motricidade.

Para a seleção dos artigos a serem analisados, dentro do universo destes 16 periódicos, foram adotados os seguintes critérios:

1) Os artigos selecionados deveriam ter sido publicados entre os anos de 2005 a 2010;

2) Para serem considerados artigos válidos para o desenvolvimento deste trabalho foi considerada a presença dos termos Educação Física, Educação Física escolar, Ensino Básico, Educação Infantil, Ensino Fundamental e Ensino Médio no título ou no resumo do artigo. Uma vez que o foco deste estudo é verificar a temática da Educação Física escolar, mais estritamente no universo do Ensino Médio, entendemos que estes termos possam vir a ter relaçōes com o tema em estudo, auxiliando, desta maneira uma delimitação apropriada.

Para a classificação dos artigos quanto à sua temática, optou-se por adotar a proposição de ANTUNES et al. ${ }^{14}$, para classificação de acordo com o tema em estudo, sendo que as categorias estão relacionadas às áreas temáticas de estudo da Pedagogia da Educação Física escolar (PEFE). Porém, mostrou-se necessário e pertinente fazerem-se duas adaptações em relação ao exposto por ANTUNES et al. ${ }^{14}$. Na proposição original há um total de sete categorias para a realização da classificação, e a sétima categoria nomeada "NãoEscolar" - categoria que abarca trabalhos que não abordam a temática da Educação Física escolar - foi desconsiderada. Isso por que todos os artigos a serem categorizados trazem a temática da Educação Física no Ensino Médio, e consequentemente, tratam da Educação Física escolar.

A outra adaptação que se realizou em relação ao estudo de ANTUNES et al. ${ }^{14}$, foi justamente adequar as categorias de classificação que o autor propóe para que estas dialoguem com a temática da Educação Física escolar no contexto do Ensino Médio.

Uma vez concluídas as adaptações metodológicas já descritas, chegou-se às seguintes categorias de classificação para produção acadêmica em Educação Física escolar no Ensino Médio: 1) Finalidade: investigação sobre fins ou objetivos finais da Educação Física escolar no Ensino Médio (proposição, compilação ou análise das suas finalidades e implicações); 2) Caracterização: descrição das aulas de Educação Física escolar no Ensino Médio, em suas dimensões psicológica, comportamental, histórica e social, assim como suas inter-relaçóes com contextos sociais mais amplos. Representam esta categoria trabalhos de cunho descritivo, do tipo levantamento e observacional; 3) Processo Ensino-Aprendizagem: estudo dos componentes envolvidos na otimização da aprendizagem no contexto da Educação Física escolar no Ensino Médio; 4) Formação de professores: trabalhos com a temática voltada para o processo de formação de professores para o contexto da Educação Física escolar no Ensino Médio; 5) Epistemologia: estudos nos quais se observam investigaçóes sobre a natureza do conhecimento da PEFE. Ou seja, estudo dos postulados, conclusōes, métodos das diferentes subáreas da PEFE tendo como cenário a Educação Física escolar no Ensino Médio; 6) Indefinido: trabalhos nos quais não é possível identificar uma temática central, ou quando aparecem mais de um dos temas citados acima, sem que haja uma predominância passível de identificação. 


\section{Resultados}

Analisando os 16 periódicos selecionados foi possível encontrar um total de 3313 artigos publicados entre os anos de 2005-2010, dos quais 287 (8,66\%) remetem-se à temática da Educação Física escolar (neste grupo encontram-se artigos referentes à Educação Física escolar na Educação Infantil, Ensino Fundamental, Ensino Médio e com outras temáticas diversas que se remetem ao âmbito da Educação Física escolar). Os outros $3026(91,34 \%)$ artigos observados tratam de outras temáticas que não apresentam como foco principal, ou mesmo temáticas relacionadas à Educação Física escolar (neste grupo enquadram-se temas de áreas como: Biodinâmica - Biomecânica, Bioquímica, Anatomia, Cinesiologia, Aprendizagem Motora, Controle Motor, Crescimento e Desenvolvimento Humano, etc. - Sociologia, Psicologia, Antropologia, Filosofia, Estudos de aspectos do Comportamento Humano, dentre outros).

No que diz respeito à produção de conhecimento no campo da Educação Física escolar, vemos que dos 287 artigos produzidos, 31 (10,80\%) remetem-se ao universo da Educação Física no Ensino Médio.

Pensando no valor total de publicações no período temporal em questão (3313 artigos entre os anos de 2005-2010) vemos que os 31 artigos referentes à temática da EF no EM representam 1,06\% desta produção de conhecimento.

\section{Discussão}

Tendo em mente o objetivo de descrever e caracterizar a inserção da temática Educação Física escolar no Ensino Médio como objeto de estudo da produção de conhecimento acadêmico-científico no âmbito dos periódicos nacionais de Educação Física e Esporte no período 2005-2010, foi possível observar que os resultados apontam uma relativa restrição no número de publicações com a temática da Educação Física escolar no Ensino Médio, se comparada isoladamente dentro do total dos 3313 artigos analisados (31 artigos entre 3313). Isto nos revela que, aparentemente, a área em questão recebe uma atenção de certa forma diminuta, no que diz respeito a pesquisas, trabalhos, publicações, e consequentemente dos respectivos pesquisadores e estudiosos, considerando os limites e delimitações apresentados neste empreendimento acadêmico aqui apresentado.
A TABELA 1 apresenta a classificação dos 31 artigos referentes à Educação Física escolar no Ensino Médio (EFE no EM) de acordo com a sua temática - tendo como referencial a proposta de classificação de ANTUNES et al. ${ }^{14}$, com as devidas adaptaçōes:

TABELA 1 - Classificação dos artigos referentes à Educação Física escolar no Ensino Médio quanto à sua temática.

\begin{tabular}{lc}
\hline Temática do Artigo & Total \\
\hline Finalidade & 7 \\
Caracterização & 6 \\
Processo Ensino-Aprendizagem & 8 \\
Formação de Professores & 0 \\
Epistemologia & 2 \\
\hline Indefinido & 8 \\
\hline
\end{tabular}

ANTUNES et al. ${ }^{14}$ adaptada.

Com base na TABELA 1 é possível constatar que há certa variabilidade na temática dos artigos produzidos, sendo que a maioria dos estudos está nos campos do Processo Ensino-Aprendizagem e Indefinido (25,80\% cada), seguidos por Finalidade $(22,6 \%)$, Caracterização $(19,35 \%)$, Epistemologia $(6,5 \%)$ e Formação de Professores (0\%).

Entretanto, quando observamos a produção de conhecimento em Educação Física no Ensino Médio, dentro do universo da Educação Física escolar, encontramos um panorama um tanto quanto diferente do exposto acima. Dos 287 artigos que expressam a produção de conhecimento na área em questão, 31 (10,8\%) remetem-se à Educação Física escolar no Ensino Médio.

Este índice de 10,8\% encontrado poderia ser de certa maneira, e guardadas as devidas proporçôes, refletir uma questão temporal da divisão dos ciclos da Educação Básica: o Ensino Médio tem uma duração de três anos (do $1^{\circ}$ ano ao $3^{\circ}$ ano). A Educação Infantil geralmente é oferecida no mercado a partir dos três anos de idade e também é composta por três anos de duração. Já o Ensino Fundamental é composto por nove anos (do $1^{\circ}$ ao $9^{\circ}$ ano), ou seja, condensa um período temporal maior. E dentro deste panorama 
poderíamos esperar que talvez exista um fator que possa vir a influenciar a produção dos estudos da área, e que estes acabem por se debruçar sobre o Ensino Fundamental em detrimento da Educação Infantil e do Ensino Médio. Ou seja, acreditamos existir uma questão temporal que possa influenciar este quadro observado. Mas, para além disto, e corroborando com outros autores da área, concordamos que há uma aparente falta de investimentos sobre a produção de conhecimento acadêmico-científico com a Temática do Ensino Médio, sobretudo no que diz respeito aos aspectos qualitativos e quantitativos, como os próprios dados deste trabalho demonstram.

Ou seja, aparentemente, há um investimento restrito para o desenvolvimento da produção de conhecimento acadêmico-científico no campo da Educação Física no Ensino Médio. E considerando o fato de o Ensino Médio ser o ciclo de encerramento da Educação Básica, que compreende a educação de adolescentes que em breve iniciarão a vida adulta, acreditamos que o Ensino Médio mereceria uma investigação mais ampla, quantitativa e qualitativamente falando.

Também acreditamos que um estudo mais aprofundado que averiguasse e fizesse a distinção da produção de conhecimento no Campo da Educação Física escolar como um todo (considerando todas as suas vertentes, não só a Educação Infantil, Ensino Fundamental e Médio) pudesse vir a contribuir para esta discussão.

No que diz respeito à produção acadêmica referente à Educação Física escolar no Ensino Médio, podemos vislumbrar alguns fatos relevantes e que fomentam uma discussão um tanto quanto interessante, sobretudo no campo da Epistemologia e da Formação de Professores.

Primeiramente, podemos observar, a partir da análise dos resultados, que aparentemente e de maneira geral, o processo de Ensino-Aprendizagem juntamente com as temáticas Finalidade e Caracterização são temáticas que têm recebido certa atenção e se apresentam, relativamente, bastante exploradas, revelando assim, que possivelmente, os autores que se desdobram sobre as questōes inerentes às temáticas em questão, reconhecem existir legitimidade e pertinência nestes temas.

Os dados encontrados nos levam a pensar que, aparentemente, a produção de conhecimento com essas temáticas podem refletir, até de maneira singular, uma preocupação não raramente observada ao longo de toda a escolarização, mas, sobretudo no Ensino Médio. A adolescência é uma fase de transição na vida do indivíduo, uma fase repleta de mudanças físicas, orgânicas, cognitivas e emocionais, uma fase repleta de conflitos, uma busca por identidade, por se reconhecer, por pertencer a um grupo social, a uma comunidade ${ }^{18-20}$. Podemos, inclusive, nos arriscar em dizer que é uma das fases mais complexas do desenvolvimento humano. E dentro desta linha de raciocínio, a Educação Física, componente curricular que ira lidar com os aspectos relativos ao movimento humano, à cultural corporal de movimento, ao movimentar-se humano, precisará lançar mão de diversos recursos para garantir que suas intenções educativas, objetivos sejam alcançados. E somado a isso ainda há o fator de Ensino Médio ser um ciclo educacional de aparente complexidade ${ }^{10}$. Isto posto, de que maneira então veríamos a Educação Física no Ensino Médio, como a trataríamos?

Ainda dentro deste panorama, e analisando os dados obtidos para a categoria Ensino-aprendizagem, que se destaca, surge a seguinte questão: Como este destaque poderia favorecer o aperfeiçoamento de programas curriculares, sobretudo no que diz respeito ao apoio ao docente?

Pensando então no Ensino Médio como um ciclo de escolarização complexo e com singularidades, é possível perspectivar que, por exemplo, profissionais da área da Educação Física, caso se faça necessário podem recorrer a este referencial teórico para pensar, repensar, refletir, discutir, problematizar, avaliar ou mesmo modificar sua prática diária em sala de aula, sobretudo no que tangem as questóes do processo de Ensino-Aprendizagem, Finalidade e Caracterização, a fim de, em meio a esse ambiente em profunda e constante transformação, corroborar para que o papel social da Educação Física no Ensino Médio se cumpra, e seja significativo na formação dos alunos.

Ou seja, o professor, a grande figura responsável por mediar este processo educacional, poderá, por exemplo, recorrer a uma base teórica para amparar sua prática diária, para tentar encontrar soluções para possíveis dilemas, ou mesmo para se atualizar. E no que diz respeito às três temáticas em questão, muito possivelmente irá encontrar o que procura. Este professor conseguiria, na nossa opinião, encontrar amparo teórico que o ajudasse a pensar a Educação Física no Ensino Médio sobre a perspectiva do processo de Ensino-Aprendizagem, Finalidade e Caracterização.

Vemos então que, segundo os dados obtidos, a grande parcela dos trabalhos produzidos está focada nas três temáticas acima expostas, revelando que, talvez, as características singulares do Ensino Médio (no que diz respeito aos alunos e aos objetivos 
educacionais) possam trazer implicações muito particulares sobre o desenvolvimento da Educação Física, gerando, desta forma, uma demanda em se pensar de maneira mais cuidadosa o ensino e a aprendizagem, a finalidade e as características do componente curricular.

Já no que diz respeito ao campo das pesquisas de cunho Epistemológico, uma possível e aceitável explicação para os dados encontrados, em comparação, por exemplo, aos achados de ANTUNES et al. ${ }^{14}$ seja uma aparente mudança de paradigma. O estudo de ANTUNES et al. ${ }^{14}$ revelou uma intensa produção de conhecimento no campo da Epistemologia, revelando que no período temporal estudado (1999-2003) as questóes do objeto de estudo da Educação Física, assim como a natureza do conhecimento do campo da Educação Física, estavam em evidência.

Neste estudo, que considerou o período temporal 2005-2010, vemos que os dados revelam uma maior concentração de estudos no campo do EnsinoAprendizagem e da Finalidade. Revelando que no houve uma aparente mudança de foco nos estudos de 1999-2003 para 2005-2010.

Entendendo a Educação Física como uma disciplina escolar, que pode caracterizar-se como uma prática social e de intervenção, e que traz consigo aspectos muito particulares relacionados à intervenção, qualificada a partir de conhecimentos academicamente orientados, e dentro deste panorama, considerando que a Educação Física escolar, legitimada pela Lei de Diretrizes e Bases da Educação $\mathrm{Nacional}^{3}$, no art. $26^{\circ} \$ 3^{\circ}$, entendemos que numa perspectiva de intervenção, uma relação precária do ponto de vista da concepção epistemológica com a formação de professores (Epistemologia com 6,5\% e Formação de Professores com 0,0\% foram as duas temáticas menos exploradas no âmbito da produção de conhecimento), pode resultar em limitações na prática profissional do professor na sala de aula, e consequentemente no processo de ensino-aprendizagem.

CAPARRós e BrachT ${ }^{20}$ questionam justamente qual seria o espaço e o lugar de uma didática da Educação Física, discutindo os papéis da didática e da teorização pedagógica na sua possível orientação da prática docente, e também, qual seria o papel de uma didática repensada (não vista como um mero instrumento técnico e, sim, na perspectiva do professor de educação física como pesquisador de sua própria prática).

Para os autores a discussão destas questôes da didática ("por que ensinar", "o que ensinar", "como ensinar", "quando ensinar" e o "como avaliar") deveria estar mais fortemente presente no processo de formação de professores, na produção de conhecimento academicamente estruturado - com a devida rigorosidade epistemológica - assim como numa atitude de autoria e autonomia por parte dos professores no sentido de uma apropriação e (re)construção dos conhecimentos necessários para desenvolver a prática pedagógica. Acreditamos que um auxiliador para tal conjectura seja justamente se ter um referencial teórico pautado em questões como o processo de Ensino-Aprendizagem e Epistemologia, que considerassem a Educação Física como área de Intervenção (e não como uma Ciência, por exemplo), e que culminasse nas questões da prática docente - em outras palavras, no dia-dia do professor em sala de aula - aliadas às investigaçóes no campo da Formação de Professores.

Ainda dentro da discussão das questôes epistemológicas da Educação Física escolar no Ensino Médio, trazemos à luz desta discussão a questão da Identidade Epistemológica. Pensemos nas possíveis consequências favoráveis de uma análise da identidade epistemológica da área e seus efeitos sobre as configuraçôes curriculares dos programas de Educação Física no Ensino Médio, trazendo, desta forma, impactos expressivos sobre a caracterização da área, $o$ que por sua vez, favoreceria uma melhor consistência no processo de sistematização das intenções educativas. Assim sendo, poder-se-á estabelecer uma clarificação dos propósitos de componente curricular, e, portanto, produzir efeitos mais pertinentes junto ao processo de formação inicial e permanente dos educadores e educadoras nos cursos universitários de formação de professores.

Um apontamento pertinente que nos vem à mente neste momento e que se torna relevante para a discussão dos dados em questão vem de DARIDO $^{2}$ et al. ${ }^{3}$. A autora afirma que em pesquisa realizada por ela, ficou evidente que há uma falta de tradição da área (da Educação Física) no encaminhamento dos conteúdos em uma dimensão conceitual. Observa-se muito o trabalho da dimensão procedimental dos conteúdos. No estudo em questão foram observados sete professores de Educação Física do Ensino Fundamental e Médio, e foi possível verificar que os professores não trabalham com conhecimentos acadêmicos em suas aulas.

E ainda vislumbrando os apontamentos de CAPARRÓs e BRACHT ${ }^{21}$ e DARIDO et al. ${ }^{22}$, acima citados, nos chama a atenção o fato de que no levantamento de dados realizados neste trabalho, não haverem artigos 
publicados que abordem a temática da formação de professores. NóvOA ${ }^{15}$ em seu texto "Os Professores na Virada do Milênio: do excesso dos discursos à pobreza das práticas" analisa o que ele chama realidade discursiva que marca grande parte dos textos sobre educação no fim do século XX, sobretudo no que diz respeito à retórica dos referidos textos acerca do papel fundamental a ser desempenhado pelos professores na construção da "sociedade do futuro". Um dos pontos a que o autor se refere como sendo de extrema importância é justamente a Formação de Professores. Segundo o autor, não há como pensar em nenhum tipo de mudança na Educação (para a melhor) que não passe pela Formação de Professores.

Acreditamos ainda que há uma fronteira muito tênue entre a Formação de Professores e o campo da Epistemologia. E ao observarmos a escassez na produção de conhecimento, sobretudo no campo da Formação de Professores, é possível questionar que o fato de não se estudar o próprio processo, pode significar em possíveis limitaçōes ou até mesmo precariedades no próprio processo formativo, e posteriormente no desempenho da profissão.

Pensando no campo da Epistemologia é possível a seguinte problematização: o fato de não haver número relevante de investigações e publicações acerca das origens deste conhecimento da PEFE, assim como do objeto de estudo da mesma, é possível perspectivar a geração de reflexos latentes nos princípios da didática, principalmente nos que dizem respeito à construção do currículo da Educação Física escolar e nos princípios didáticos dos conhecimentos conceituais, procedimentais e atitudinais do processo educativo.

Outro aspecto relevante é justamente a questão de que não havendo uma produção de conhecimento academicamente consistente (que leve em consideração os padrões e princípios éticos, metodológicos e da pertinência do tema e das finalidades deste referencial teórico, tal qual ECO ${ }^{23}$ e SEVERINO ${ }^{24}$ nos revelam como sendo pontos fundamentais), com a devida rigorosidade epistemológica (que é um elemento importante para contribuir numa dimensão da profissionalidade docente, que transcende prescrições de natureza técnica, instrumentais e pragmáticas), é possível de se esperar reflexos no que é chamado processo de formação continuada (tal qual na concepção de $\mathrm{NoVOA}^{15}$ ). Formação esta que vai para além da graduação em ensino superior e que passa a se configurar como um processo cíclico e sem um fim determinado.

E nesta perspectiva temos dúvidas quanto às alegações de domínio exclusivo dos profissionais da Educação Física sobre a educação Corporal e de Movimento, uma vez que entendemos que há uma precariedade na produção de conhecimento que sustentaria essa posição de cunho corporativista.

Buscando dados na literatura que possam auxiliar numa análise de hipóteses para a baixa produção acadêmica em Educação Física, mais especificamente no Ensino Médio, os apontamentos de ANTUNEs et al. ${ }^{14}$ podem mostrar-se muito pertinentes para entendermos possíveis causas desta baixa produção de conhecimento no campo da Educação Física escolar. Para os autores, há um distanciamento das instituiçōes de ensino superior em relação ao sistema básico de ensino. Ou seja, quem está no dia-dia do cotidiano escolar não está a par do que os pesquisadores estão a produzir, e os pesquisadores, por sua vez, não possuem dados suficientes que apontem no sentido de como os professores atuam, (de sua prática docente, em sala de aula). Quando há estudos de natureza da caracterização (que poderiam, por exemplo, descreverem, elucidarem, investigarem questóes do ambiente escolar, seus sujeitos, espaços, as aulas), é possível que o delineamento do estudo esteja voltado às questôes específicas de interesse do pesquisador ${ }^{14}$. Ou seja, há a utilização do espaço escolar para a realização da pesquisa, porém não há uma aproximação entre pesquisador e professor.

Outro fator que pode revelar-se como uma possível causa para este quadro apresentado, nos é oferecido por um panorama histórico da Educação Física nacional, e está atrelado ao efeito chamado de "movimento disciplinar" da Educação Física ${ }^{25-26}$, que originalmente foi desencadeado nos Estados Unidos da América (mais detalhes em HeNRY ${ }^{27-28}$ ). Este movimento buscava elevar o "status" acadêmico da área para justificar a sua presença no contexto universitário (da universidade). No Brasil, em consequência a este movimento, surgiu a consideração de que as pesquisas com as temáticas da epistemologia e metodologia das ciências naturais e exatas seriam os melhores caminhos para que esta elevação de "status" acadêmico da Educação Física.

Em contrapartida, as pesquisas referentes à epistemologia e metodologia das ciências humanas (e aqui se enquadram pesquisas de cunho pedagógico), passaram a ser desestimuladas.

Tendo em mente os dados obtidos com este trabalho, e assumindo a Educação Física como área de intervenção, legitimada por conhecimentos academicamente orientados, nos chama a atenção constatar que, em volume de publicações, esta produção de conhecimento encontrada, é de certa 
maneira restrita. E, a partir disto, podemos sinalizar possíveis limitações e precariedades que podem ir para além das questôes de legitimação da área.

Reconhecendo o valor e legitimidade da Educação Física no Ensino Médio, e acreditando que há uma tênue fronteira entre ambos os campos (Epistemologia e Formação de Professores), podemos perspectivar efeitos não muito favoráveis sobre a prática docente, sobretudo no que tange as questóes didáticas do "por que ensinar", "o que ensinar", "como ensinar", "quando ensinar" e o "como avaliar". Também sinalizamos para as possíveis consequências desta restrita produção de conhecimento com a temática em questão sobre as questōes de legitimação da área, da didática diária do professor em sala de aula, e sobre o processo de formação de professores.

Ainda ressaltamos ser fundamental um investimento em produção de conhecimento com a temática da Educação Física escolar no Ensino Médio. Também destacamos a necessidade de desenvolvimento de um entrecruzamento estratégico das dimensões epistemológicas da área com as pesquisas de caráter aplicado, perpassando pelas questôes inerentes ao processo de formação docente (inicial e permanente).

\begin{abstract}
Physical Education in high school as an object of study of academic-scientific production in national journals

The aim of this study was to describe and characterize the insertion of Physical Education in High School" as a scientific subject in national Physical Education and Sport Journals (period 2005-2010). We explored 3313 articles published in journals ranked in extracts A and B of the Qualis/CAPES System. Of these, 31 articles (1.06\%) brought the theme of Physical Education in High School. Based on Antunes et al. ${ }^{14}$, it was possible to classify these 31 articles in the following 6 categories: Teaching-Learning Process and Indefinite: 8 articles (25.80\% each) Purpose: 7 (22.6\%), Characterization: 6 (19.35\%), Epistemology: 2 (6.5\%) and Teachers Training Process: no articles (0\%). These data show that there is a restriction in knowledge production in the Physical Education and Physical Education in High School areas, suggesting that is needed to develop a strategic intersection between epistemologist dimension of the area, going through researches and teachers trainings process.
\end{abstract}

KEY WORDS: Physical education; High school; Academic production.

\title{
Referências
}

1. Neira MG. Por dentro da sala de aula: conversando sobre a prática. 2a ed. São Paulo: Phorte; 2010. Cap. 3.

2. Pérez Goméz AI. As funções sociais da escola: da reprodução à reconstrução crítica do conhecimento e da experiência. In: Gimeno Sacristán JE, Pérez Gómez, AI. Compreender e transformar o ensino. Porto Alegre: Artmed; 2000.

3. Brasil. Lei de Diretrizes e Bases da Educação Nacional, no 9.394, 20 de Dezembro de 1996. Estabelece as diretrizes e bases da educação nacional. Diário Oficial da União, Brasília (DF). 199624 dez.

4. Coll C. Psicologia e currículo: uma aproximação psicopedagógica à elaboração do currículo escolar. São Paulo: Ática; 1997.

5. Coll C, Pozo JI, Sarabia B, et al. Os conteúdos na reforma: ensino e aprendizagem de conceitos, procedimentos e atitudes. Porto Alegre: Artmed; 2000.

6. Libâneo JC. Didática. São Paulo: Cortez; 1994.

7. Correia WR. Educação física no ensino médio: questōes insólitas. In: Carreira Filho D, Correia,WR, organizadores. Educação física escolar: docência e cotidiano. Curitiba: CRV; 2010. v. 1, p. 165-76.

8. Freitas MTA. A abordagem sócio-histórica como orientadora da pesquisa qualitativa. Cad Pesqui. 2002;1:21-40.

9. Daólio J. Educação física e o conceito de cultura. Campinas: Autores Associados; 2004.

10. Correia WR. Educação física no ensino médio: subsídios para um projeto crítico e inovador. Motriz: Rev Educ Fís. 2009;15:740.

11. São Paulo (Estado). Secretaria de Estado da Educação. Proposta curricular do Estado de São Paulo. Caderno Introdutório: Educação Física. São Paulo: SEE; 2008. 
12. Darido SC. Os conteúdos da educação física escolar: influências, tendências, dificuldades e possibilidades. Perspec Educ Fí Esc. 2001;2:5-25.

13. Betti M. Valores e finalidades na educação física escolar: uma concepção sistêmica. Rev Bras Ciênc Esporte. 1994;16:14-21. 14. Antunes FHC, Dantas LEPBT, Bigotti S et al. Um retrato da pesquisa brasileira em educação física escolar: 1999-2003. Motriz: Rev Educ Fís. 2005;11:179-84.

15. Nóvoa A. Os professores na virada do milênio: do excesso dos discursos à pobreza das práticas. Educ Pesqui. 1999;25:11-20.

16. Bracht V. Educacao fisica no 1. Grau: conhecimento e especificidade. Rev Paul Educ Fís. 1996; v. SE 2, p. 23-8.

17. Lovisolo H. Educação física: a arte da mediação. Rio de Janeiro: Sprint; 1995.

18. Carvalho VBC. Desenvolvimento humano e psicologia. Belo Horizonte: UFMG; 1996.

19. Calligaris C. A adolescência. São Paulo: Publifolha; 2000.

20. Cole M, Cole S. O desenvolvimento da criança e do adolescente. Porto Alegre: Artmed; 2003.

21. Caparrós FE, Bracht V. O tempo e o lugar de uma didática da educação física. Rev. Bras Ciênc Esporte. 2007;28:21-37.

22. Darido SC, Galvão Z, Ferreira LA, Fiorin G. Educação física no ensino médio: reflexōes e ações. Motriz: Rev Educ Fís. 1999;5:138-45.

23. Eco U. Como se faz uma tese em ciências humanas. Milano: Casa Editrice Valentino Bompiani; 1977. p. 16-177.

24. Severino AJ. Metodologia do trabalho científico. 21a ed. rev. ampl. São Paulo: Cortez; 2000. p. 73-131.

25. Tani G. Perspectivas da educação física como disciplina acadêmica. 2o. Simpósio Paulista de Educação Física; 1989; Rio Claro, BR. Rio Claro: Universidade Estadual Paulista; 1989. v.2, p. 2-12.

26. Tani G. Cinesiologia, educação física e esporte: ordem emanente do caos na estrutura acadêmica. Motus Corporis 1996; 3:9-49.

27. Henry FM. Physical education: an academic discipline. J Health Phys Educ Recreat. 1964;35:32-8.

28. Henry FM. The academic discipline of physical education. Quest. 1978;29:13-29.

\begin{tabular}{r|l} 
ENDEREÇO & \\
Diogo Inacio Dias & Recebido para publicação: 03/09/2012 \\
Estrada dos Galdinos, 250 & 1a. Revisão: 18/12/2012 \\
06710-400 - Cotia - SP - BRASIL & 2a. Revisão: 31/12/2012 \\
e-mail: diddias@hotmail.com & Aceito: 14/02/2013 \\
&
\end{tabular}

Rev Bras Educ Fís Esporte, (São Paulo) 2013 Abr-Jun; 27(2):277-87 • 287 